International Journal of Instruction e-ISSN: 1308-1470 • www.e-iji.net

Article submission code: 20200125183714

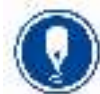

January $2021 \bullet$ Vol.14, No.1

p-ISSN: 1694-609X

pp. 345-364

Received: 25/01/2019

Revision: 24/06/2020
Accepted: 15/07/2020

OnlineFirst:18/10/2020

\title{
The Effectiveness of Infographic via Interactive Smart Board on enhancing Creative Thinking: A Cognitive Load Perspective
}

\section{Osamah Mohammad Ameen Aldalalah}

Assoc. Prof., Taibah University - Faculty of Education - Department of Educational Technologies, Saudi Arabia, odalalah@taibahu.edu.sa

The purpose of the present study was to examine The Effectiveness of the Infographic Pattern through the Interactive Smart Board on the Creative Thinking of Educational Technology Students: A Cognitive Load Perspective. This study utilized the quasi experimental type methodology. The independent variables were the Infographic Pattern methods (text and image, sound and image). The dependent variables were the creative thinking, which will be determined by the final mark on the post-test. The study samples consisted of 33 undergraduate educational technology students, and were randomly selected, via simple random sample. ANOVA procedure was used to determine the significant differences of the pretest scores among the two methods. An analysis of covariance, MANCOVA, was carried out to examine the main effects of the independent variables on the dependent variables. The findings of this study showed that students who have learned through the Infographic Pattern sound and image achieve design efficiently better in their post-test scores than those in the Infographic Pattern text and image. The results also showed that the effect of using infographic through the interactive smart board on the development of creative thinking skills among students of educational technology was medium degree.

Keywords: infographic, smart board, creative thinking, cognitive load, thinking

\section{INTRODUCTION}

The current era has witnessed a remarkable development in all areas of life around us, including the field of education, which made us notice in our time a great increase and accumulation of information, knowledge, and data that are characterized by difficult and complex delivery to learners in spite of tremendous technical developments and the qualitative shift in the process (Aldalalah, Shatat \& Ababneh, 2019). This motivated educators to create and bring about what serves the educational process, saves time and effort, facilitates the learning process, reduces information, and simplifies the process of delivering it to learners (Yousef, 2019).

Infographic design has a great effect in facilitating and simplifying the display, presentation and reading of this accumulated information for learners by presenting it attractively and interestingly because of its diverse designs that provide learners with a

Citation: Aldalalah, O. M. A. (2021). The Effectiveness of Infographic via Interactive Smart Board on enhancing Creative Thinking: A Cognitive Load Perspective. International Journal of Instruction, 14(1), 345-364. https://doi.org/10.29333/iji.2021.14120a 
new form of visualization in collecting, presenting and communicating information and data to them (Afify, 2018). Infographics is changing the thinking process of the learner in terms of information and data, especially if presented through interactive methods and environments in which continuous developments in ICTs have played a major role and brought about a tremendous breakthrough in the field of teaching and learning (Bicen \& Beheshti, 2017). This has led to the emergence of electronic and digital solutions that increase interaction in the learning process. One form of e-solutions that facilitated the process of teaching and learning was the interactive smart board (Mansour, 2015). The interactive smartboard relies on written texts, in addition to a set of elements as well as illustrated, drawn and animated stimuli and their role in developing thinking skills, especially creative thinking (Morsi, 2017). However, the content of the study is difficult and can only be understood by merging the elements of the content together to build mental plans, in order to address all of them at once at the same time, may lead to an increase in the load on working memory (WM). Content can be limited by the provision of educational material as elements from the easy to the difficult; hence, learning materials needs to be designed in a way that contributes to building knowledge and maximizing learning (Aldalalah, 2011). Multimedia is a stimulus that connects the learner's memory with the material before it and makes the learner focus his attention on the finer details of the instructional material. This is a double encoding of material in the learner's memory that affects his recalling and remembering information after a while; therefore, the cognitive load theory came to emphasize practical practices that could be applied to improve the training and practical performance of learners during learning through the use of a number of methods and techniques to minimize the effects of the emergence of overlapping cognitive load as a result of the use of different learning materials to ensure the effectiveness of learners' learning (Ercan, 2014).

\section{The concept of infographics}

Infographics are a kind of drawings that integrates all the techniques of education in providing information concisely, artistically and attractively, combining technical, educational and cognitive development, i.e., transforming data and information into images and graphics that are clearly understood (Abo areban, 2017). Further, Al-Otaibi (2018) points out that infographics are a technical term that refers to the conversion of complex information and data into graphic images that are easily accessible to those who see them without having to read a lot of texts. Infographics are one of the most important and effective means of presenting information, especially through social networks. It combines ease, speed and entertainment in displaying information and communicating it to the recipient (Dunlap \& Lowenthal, 2016).

Infographics aims to provide complex information rapidly and clearly, improve cognition by employing graphics and enhance the individual's visual system's ability to recognize patterns and trends because the brain processes visualized information more easily and less complexly then it needs to process texts (Yıldırım, 2016). Infographics is a type of image that blends data in an image to help individuals communicate in a way that enables them to quickly understand and comprehend it. Infographics is used as a tool for displaying complex and difficult information simply and concisely through its 
high quality and ability (Islamoglu, Ay, Ilic, Mercimek, Donmez, Kuzu. \& Odabasi, 2015) Aldalalah, Ababneh, Bawaneh \& Alzubi, (2019) focuses on the importance, effectiveness, and impact of multimedia in presenting information through models that are appropriate to students' learning and how well they process information mentally.

Infographics has the ability to simplify information, data and knowledge and make it easy to rely on visual effects. Moreover, it translates information and textual and digital data to graphics and images that are more interesting and easy to receive, in addition to reducing time and effort; hence, the learner does not need to read a text of one page or more as infographics provides the ability to keep information for a longer time, as well as it encourages and promotes the principle of in-depth thinking and the organization and interconnection of information (Simiciklas, 2012). Infographics is used In social media and advanced content, illustrations, charts, or human charts where it can offer a variety of options in content, track events by displaying the calendar sequence. Further, it is used to compare and balance two things to show their differences (Çifçi, 2016).).

Yildirim (2016) notes that infographics maybe interactive where information, knowledge, images, and symbols, as well as sound and animations are displayed. It may be non-interactive and provide information in the form of static texts, images, symbols and forms. Shaltout (2016) believes that infographics have three types in terms of the nature of the presentation: the first: fixed infographics, which is a fixed design and graphic drawing in the form of images and drawings with information on a specific subject that clarify and explain the idea consistently. The second: Motion infographics, which has two types: normal video shooting that takes into account information and explanatory data that will appear in the motion video, in order to show some facts and concepts during the display of the video to the viewer. This is one of the types that needs creator's creativity in producing the video; and motion graphics which is the complete mobile design of data, clarifications, and information. This type requires a lot of creativity and the choice of expressive movements that help produce it in a delightful and interesting way. This type is the most widely used and popular now; and the third: interactive infographics which enable the viewer to control through some control tools from buttons and software. In order for the viewer to control the infographics, the design of this type requires the design and translation of some parts that include the required control and translation.

Further, there is a number of steps in which the process of designing infographics passes, the most important of which are: identifying the design priorities and what is needed to be achieved through this design; identifying the idea, target group and data on the subject; analyzing, evaluating and classifying the data and information obtained by using modern references and working on filtering them; planning to do the work and arranging content by creating a mental map with the right visualization, choosing the most suitable tool for design and experimenting with it to make sure that it is ready for use (Matrix \& Hodson, 2014).

In the field of education, infographics works on simplifying complex and large information to make it easy to understand based on the visual effects on information delivery. This is added to the speed in the presentation of information and 
communicating it to the learner through the elements of attraction and excitement. Therefore, learning is more organized and coherent, making it easier to recall and remember. This is in addition to facilitating the formation of the mental image of students, as well as facilitating the work of the teacher, especially for children at an early stage because they prefer drawings over the structural texts; hence, the use of drawings with data generates mental images that are easy to understand and remember. It addresses the mind in a suitable way and helps the learner to form a comprehensive overview of the knowledge provided as well as recognizing the relationships among them providing integration of the knowledge that focuses on the concept rather than on the amount and preservation of information (Jeroui, 2014). When thinking about using infographics, teachers should consider the principles and standards of its instructional design. That is the subject should be suitable for conversion to infographics. Teachers should work on analyzing the content of the subject and ensure the correctness, update and authenticate the information taking into account the sequence. It is also important to choose the media that fit the idea and the goal and present it in a simple and an uncomplicated way (Shaltout, 2019).

\section{Interactive Smart Board}

Technological developments in the field of education appear in introducing all that is new to serve the teaching/learning process through educational institutions bypassing the era of the wood chalkboard, whiteboard, blackboard, magnetic whiteboard, and projector. It was possible to connect the computer to a sensitive display screen instead of the computer screen, eliminating the use of the mouse and keyboard by using the navigation system, this can run and interact with different computer programs, as well as special programs to produce interactive lessons (Davidovitch \& Yavich, 2017). A'salmi \& Ambusaidi (2016) defined smart board as a sensitive white electronic display, which we deal with using a fingerprint sensor or a special digital pen. It is connected to a computer, a projector, and a printer. It displays all educational programs stored on a computer or on the Internet, directly or remotely. A'zuabi (2011) defined it as: An electronic device connected to a computer, where images and videos from the computer are displayed on the board. This panel is used interactively. Notes can be added, and points of interest are highlighted with the possibility to control the programs the way the user wants. He can print these notes, drawings and other things from the computer, or save them for future reference.

This smart board has high-quality technical capabilities. It is used as a large display screen instead of a small computer screen using all the software and is interacted with by touch instead of mouse and keyboard. It enables the user to handwritten comments and convert them to digital characters on videos and office programs and converts hand drawings to digital drawings such as geometric shapes. It enables the use of calipers, rulers, and protractors; further, it provides the possibility of keeping and storing the information written on the computer for later modification or print out ( $\mathrm{Al}$ hassan \& $\mathrm{Al}$ badwi, 2016). Moreover, it can be connected to the Internet for browsing or moving on to another class at the same time (distance learning) along with the teacher's image if a camera is available. It saves the teacher's time to prepare anything he wants to offer to 
students, enables him to write annotations during the lesson presentation and records comments and voice explanation. It maintains the student's time as he does not need to write what is displayed on the board because the teacher will save and offer it on flash memories or by e-mail (Jbeili, 2014).

Smart board has the characteristic of a motion element in multimedia educational programs where the learner can move and transfer drawings and shapes. Students are encouraged to use instructional technology. Alqrery (2016) shows that interactive smart board increases the learner's activity, motivation, and vitality during the learning process. Thus, the learner is at the center of the learning process, which increases his motivation to learn because of using multimedia and interacting with it through writing and feedback. In his study, Abdel Fattah (2017) emphasizes increased motivation resulting from the interactive whiteboard in addition to immediate and continuous feedback, which reflects on the effectiveness of students' behavior and activity. It enables the user to control the font size and allows the user to hide what is written and displayed when needed, and to get rid of shyness through colleagues' productive interaction with interactive white boards. Further, it increases the student's ability to retain information and knowledge for a long time; it is possible to insert images a CD or floppy disk. Further, the whiteboard contains a picture library with maps, animals, geometric shapes and backgrounds. This improves the level of educational outputs for all ages and in all subjects; solves the problem of lack of teaching staff, increases the flexibility of the educational process, and provides support for people with special needs through multimedia.

\section{Creative Thinking}

Creative thinking aims at discovering new relationships or unfamiliar ways of solving an existing problem (Morsi, 2017). Torrance \& Goff (1990) argues that creative thinking is a process of recognizing missing gaps, imposing and reconnecting hypotheses, testing their validity, expressing results, and testing and modifying hypotheses, in addition to the individual's ability to produce as distinctly as possible fluency, flexibility, and originality, in response to an exciting situation. Furthermore, creative thinking looks at things in a different and new way. It involves lateral thinking or the ability to perceive unclear patterns in anything. Innovative people have the ability to devise new ways to solve problems and meet challenges. Creativity is sufficiency, energy, and willingness that a human acquires through the systematic concentration of mental abilities, will, imagination, experiences, information and a secret of excellence in the realms of life. It enables its owner to uncover new ways to change the surrounding world and escape from boredom and repetition. It has become the main material in the processes of change and development (Al azri, 2017). Creative thinking is one of the most prestigious human activities, since scientific progress cannot be achieved without the development of creative abilities. The development of human societies is contingent upon the available stock of creative abilities (Morsi, 2017). Many researchers have considered creative thinking to be a divergent thinking in the right half of the brain, characterized by the production of many responses that may not be information received 
by the individual. It involves new information, ideas and products; attention should be paid to the quality and quantity of these products (Khasawneh, 2015).

The teacher plays an important role in the development of students' creative thinking by posing many questions to stimulate their thinking, using methods of excitement, and following-up and observing their activities continuously to reach the correct logical ends, in addition to vertical and horizontal logical organization and coherence of ideas (Katami, 2008). Creative thinking skills are fluency, which means the ability to generate (summon) a large number of rich and varied synonyms and ideas of previous information and experience in a given period of time. These include a quantitative aspect of creativity; fluency has five forms: 1. Verbal fluency, 2. Fluency of recalling, 3Fluency of expression, 4 - Fluency of ideas, and 5 - Fluency of forms (Al-Qahtani \& Yousef, 2015).

Flexibility is the change of the mental state of an individual by changing the situation, i.e., the ability to generate diverse and different ideas of the skill given; further, it is the ability to change the intellectual trends without insisting on a certain trend. Flexibility has two types: a) spontaneous flexibility which is the rapid ability of the individual to produce as many trends and ideas associated with a situation as possible, and b) adaptive flexibility. This means the ability of the individual to change the mental orientation in the face of a problem and formulate the proposed solutions and change responses according to the situations encountered. Moreover, it means the individual's ability to modify the behavior in order to conform to the situation. Originality means the ability of the individual to generate unfamiliar ideas, excellence in thinking, scarcity and the ability to access beyond the direct and familiar ideas. Further, it means being able to come up with a new idea in a specific place and time (Al Eid, 2010).

\section{Cognitive Overload Theory}

It is recognized that the theory of cognitive overload is one of the cognitive theories that have been known in this century. Many practical procedural studies in the field of psychology with a focus on the system of processing information in humans have been carried out through it to lay the foundations of educational design based on the cognitive structure in humans (Aldalalah, 2012; Mayer, \& Moreno, 2003). This theory provides a general framework for instructional material designers, as it allows them to adjust learning conditions within the environment of most teaching materials. In particular, it provides guidance to help them reduce the burden of knowledge. It is able to guide and provide evidence that would help present information in a way that stimulates the mental processes of the learner and helps make learning a success. Therefore, the instructional designer must know it as well as the ways in which the knowledge load is eliminated and the balance is achieved to facilitate and improve learning (Zoubi, 2017).

Sweller's (2006) cognitive load theory assumes that the brain has a short-term, limited capacity (working) memory that can only receive and process limited elements of information, and that there is a long-term, permanent, unlimited memory in which information is stored after processing. The temporary memory is involved in understanding and coding information in the permanent memory. If the information 
received by the temporary memory increases at the same time, this leads to an overload of mind of the learner and thus learning fails. This theory focuses on the individual's integrated cognitive structure which consists of the long-term memory in order to store the acquired knowledge and the working memory (WM) to process information, taking into account the limited capability to process information and the limited capacity that can affect the learning process, (Sweller, 2004). Cognitive load is a multidimensional cognitive structure that represents the burden that a particular task imposes on an individual who performs it in practice. Cognitive load has a causal dimension, in which a number of causal factors can represent, in essence: characteristics and features of the subject matter, i.e. the level of experience of the learner, and the task entrusted to him, i.e. the degree of difficulty and complexity of the task used, the time pressures imposed on the learner, and the various interrelations among them (Ezzeldin, 2017).

Through the demands of the task, the learning environment, and the mental effort (the actual capacity required to perform the task by the learner) that the learner is going through, the evaluation dimension is reflected in the theory of cognitive overload by identifying diverse and measurable concepts. The theory of cognitive overload is important because of using different teaching materials to ensure the activation of learners' learning that focuses on practical practices to be applied to improve their performance during learning. This is carried out by using a number of ways and means to minimize the effects of the emergence of overlapping cognitive overload (Abadi, 2014). The theory of cognitive overload suggests that many instructional designs are ineffective because they ignore the scientific and fundamental aspects of the perception and processing of information that arise when an individual learns from many different elements simultaneously (Sweller, 2006). This theory has three components: the cognitive structure and its stages of development; identification of the natural information processing system; and finally, the impact of cognitive structure and learning (Paas, Tuovinen, Tabbers \& Van, 2003).

Sweller (1994) argues that the amount of mental activity imposed on WM at a given time is cognitive load, which has been shown to have three distinct parts: intrinsic that reflects the difficulty level of materials to be learned; extraneous which is generated by the way information is provided to learners and controlled by instructional designers, this load can be attributed to the design of instructional materials; and finally, the germane cognitive load which is related to the effort needed in preparing and processing new information. Sabab (2016) referred to the levels of cognitive load as the quantitative level: the cognitive load increases, according to the increase of the number of stimuli. The color level: the cognitive load raises when the stimuli are similar; and finally, the volumetric level where the cognitive load increases by decreasing the volume of the desired exciter and decreases as the magnitude of the required exciter increases. In sum, the theory of cognitive overload is an educational theory that is closely related to the teaching and learning process. It is based primarily on our knowledge of the human cognitive structure. Models of instructional design that do not take into account the cognitive structure of humans are likely to suffer more than from randomness and ineffectiveness. Further, it allows for the identification of a mechanism to effectively support learning through the instructing and teaching processes, where attention to 
multiple and different sources of verbal and non-verbal information requires mental sources that focus on one source (Sweller, 2005).

\section{Study Problem and Questions}

The current research problem is the detection of creative thinking among students of educational technology and its development has been crystallized through the use of one of the latest technological innovations due to the scarcity of studies that dealt with the development of creative thinking in this category, especially the use of technological innovations such as auditory and visual infographics. Researchers therefore found that students need to develop their creative thinking through the use of interactive whiteboard based on the theory of cognitive load. In the light of the above, the problem can be presented and addressed by answering the following questions:

- What is the effect of employing infographics through the interactive smart board in developing the creative thinking skills of the educational technology students?

- Is there a difference in the development of creative thinking skills among educational technology students due to the different pattern of infographics (image and text, image and sound) through the interactive smart board?

\section{Research Framework}

The research framework in Figure 1 shows the relationships between the different variables under investigation.

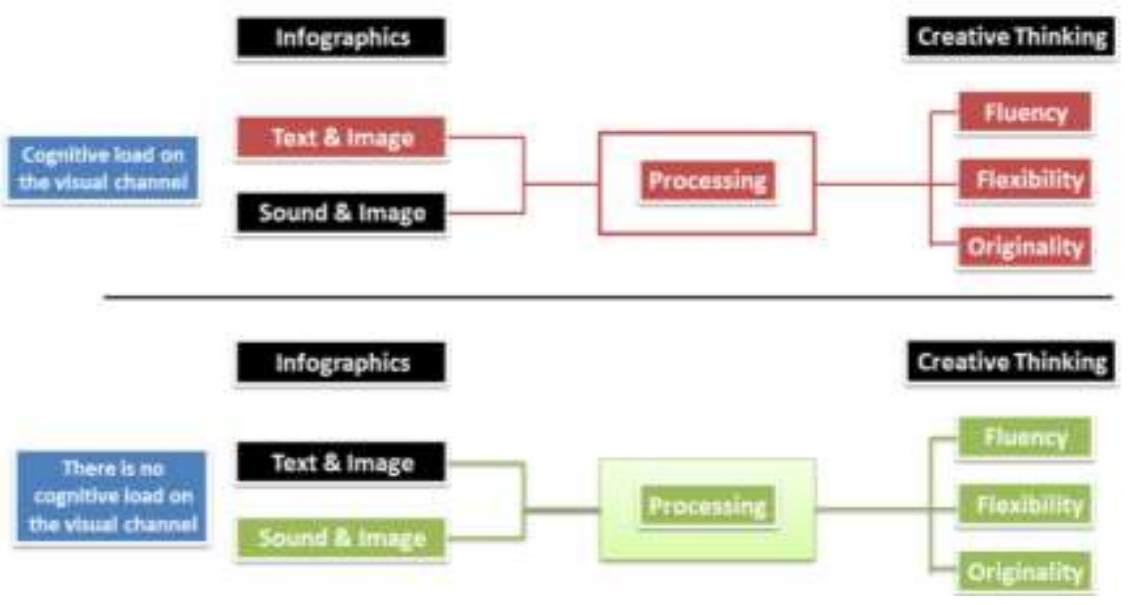

Figure 1

Research framework

The research framework depicts two variables. The independent variables are the infographics (image and text, image and sound) methods instruction and conventional instruction. The dependent variables are student's creative thinking score. The 
instruction rating variable is present in this study and has a strong contingent effect on the relationships between the independent and dependent variables. The effect of using the infographics on creative thinking will be identified by measuring creative thinking skills.

In this study cognitive load, the load of generating by the way the material is presented and which does not aid learning, that is by displaying the material through infographic patterns.

Cognitive load theory suggests that if the cognitive load exceeds our processing capacity, we will struggle to complete the activity successfully, so when we display the material through the pattern of the infographic (Text and Image), there will be an overload on the visual channel which effects on the level of creative thinking skills. The extraneous cognitive load can be reduced by the way in which materials are presented through the pattern of the infographic (Sound and Image), who distributes information through the visual and audio channel.

\section{Research Objectives}

There are two main objectives of this study:

1. Evaluating the effect of employing infographics through the interactive smart board in developing the creative thinking skills of the educational technology students.

2. Find out the effect of difference in the development of creative thinking skills among educational technology students due to the different pattern of infographics (image and text, image, and sound) through the interactive smart board.

\section{METHOD}

\section{Study population and sample}

The study population consisted of all educational technology students in the Faculty of Educational Sciences enrolled in the Bachelor program in Jordanian universities and enrolled for the second semester of the academic year 2018 - 2019. The sample of the study consisted of (33) male and female students of educational technology at Jadara University who are enrolled in the courses of designing educational software in the summer semester of the academic year 2018-2019. The first group was identified as (16) students studied through picture and sound and the second group consisted of (17) students studied through text and picture.

\section{Study Instruments}

In order to apply the study and obtain information, the researcher used Torrance Creativity Test to measure the level of creative thinking. He reviewed the Arabic translation of this test to measure the level of creative thinking in the skills of fluency, flexibility and the originality of the members of the study sample and relied on The Torrance Test Correction Manual for Formal Creative Thinking (B) (Saifuddin, 2015) 
which includes three sub-activities: the construction of images, and missing forms; while in the Arabized version, Al-Nashti's study (1983) confirmed the validity of the test from several aspects: discriminating, formative, and correlation validity. Al-Nashati (1983) verified the reliability of the test by the method of test and re-test. The findings showed that the test obtained scores of reliabilities. Moreover, the researcher presented the measure to a number of arbitrators specialized in talent, creativity, educational technology, and graphic design. He ensured the reliability of the scale through the coefficient of re-test. The correlation coefficient for the total reliability of the test was (0.87). This indicates a high-reliability coefficient suitable for the study purposes; the fluency coefficient was $(0.82)$, the flexibility coefficient was $(0.85)$, and the originality coefficient was (0.88). 0.89).

\section{Research Design}

The research design of this study is based on the concept of the cognitive over lode theory. This study followed the quasi experimental method to measure the impact of different types of infographics through the interactive whiteboard on the creative thinking of educational technology students. This study includes two independent variables and one dependent variable.

\section{Research Variables}

The present study contains two types of variables (independent, and dependent variables) that are presented as follows:

Independent Variable: The independent variables in this study were the two modes of infographics through an interactive smart board: (image and text) and second (image and sound).

Dependent variable: creative thinking among students (Fluency, Flexibility, Originality).

\section{Research Procedures}

The researcher conducted an analytical study where the references and studies related to the subject were examined in order to emphasize the importance of the current research topic and to benefit from the findings of these studies, as well as to focus on the importance of using available research tools. The educational objectives to be achieved by the educational program were determined in accordance with the curriculum of science and presented to a group of specialists in the field of education technology and special education and to teachers of science in schools. Their suggestions were taken into account and the content of the program was identified. One of the computer programs used in the design of the educational program was the lab course. The scenario of the infographics program based on the theory of cognitive load was taught through the interactive whiteboard. The program consisted of two types of infographics: in the first the content was presented with text and images, whereas the second by the audio and video. The study sample was then divided into two groups: the first group studied through text and visual infographics, and the second group studied through audio and visual infographics. The Torrance Test Arabic version was distributed to both study 
groups and was corrected; then the results were obtained and analyzed through the SPSS program.

Table 1

ANOVA of the Pre-test Scores to Measure the Equality of Groups

\begin{tabular}{llllll}
\hline & Sum of Squares & df & Mean Square & F & Sig. \\
\hline Between Groups & .740 & 1 & .740 & .130 & .721 \\
\hline Within Groups & 188.003 & 33 & 5.697 & & \\
\hline Total & 188.743 & 34 & & & \\
\hline
\end{tabular}

\section{Group's Equivalence}

A pre-test that measures before the beginning of the study. To examine the equality between groups (text/image \& sound/ image) table (1), the ANOVA procedure was used results have been shown that there is no significant difference in the pre test scores in (text/image \& sound/ image), groups. This means that the groups have the same level of prior knowledge of designing educational software and creative thinking skills of the educational technology students.

\section{RESULTS}

The analyses of the collected data were carried out through various statistical techniques such as the ANCOVA, the data were compiled and analyzed using the Statistical Package for the Social Science (SPSS) for Windows computer software.

The aim of this study is to measure the impact of two types of infographics through the interactive whiteboard on the creative thinking of educational technology by students answering the following study questions:

\section{The First Question}

What is the effect of employing infographics through the interactive smart board in developing the creative thinking skills of the educational technology students?

The student's results were divided into three groups depending on their creative thinking (Fluency, Flexibility, Originality). The low, medium and high levels can be identified based on the following equation:

$Z=\frac{\text { Highest Mark }- \text { Lowest Mark }}{\text { Nnumber of Levels }}$

Where $\mathbf{H}_{\min }=$ Highest Mark

$\mathbf{L}_{\text {min }}=$ Lowest Mark

$\mathbf{Z}=$ The difference between a level and the other.

$\mathrm{L}=$ Low, $\mathrm{M}=$ Medium, $\quad \mathrm{H}=$ high

$\mathrm{L}=\left[\mathbf{L}_{\text {min }}-\mathbf{L}_{\text {min }} \mathrm{Z}\right] . \quad \mathrm{M}=\left(\mathbf{L}_{\text {min }} \mathrm{Z}-\mathbf{L}_{\text {min }} 2 \mathrm{Z}\right] . \quad \mathrm{H}=\left(\mathbf{L}_{\min +} 2 \mathrm{Z}-\mathbf{H}_{\text {min }}\right]$

The level of creative thinking among students was divided into three levels as shown in the table (2). 
Table 2

Distribution of students' scores at the three levels of creative thinking

\begin{tabular}{llllll}
\hline & Highest Mark & Lowest Mark & Low & Medium & High \\
\hline Fluency & 93 & 39 & $39-57$ & $58-75$ & $76-93$ \\
\cline { 2 - 6 } Flexibility & 21 & 2 & $2-8$ & $9-15$ & $16-21$ \\
\cline { 2 - 6 } $\begin{array}{l}\text { Originality } \\
\text { Total }\end{array}$ & 19 & 1 & $1-7$ & $8-14$ & $15-21$ \\
\cline { 2 - 6 } & 127 & 53 & $53-77$ & $78-101$ & $102-127$ \\
\hline
\end{tabular}

To answer this question, the mean and standard deviations were calculated for the scores obtained by students in the post-test of creative thinking as shown in Table (3):

Table 3

Mean and standard deviations for the scores in the post-test

\begin{tabular}{lll}
\hline & Mean & Std. Deviation \\
\hline Fluency & 69.3 & 12.3 \\
\cline { 2 - 3 } Flexibility & 12.3 & 4.1 \\
Originality & 10.8 & 3.6 \\
\cline { 2 - 3 } Total & 92.5 & 17.4 \\
\hline
\end{tabular}

Table 3 shows that the mean and standard deviations of the degree of creative thinking skills of students who studied through infographics were moderates, Fluency skill was ranked first, flexibility skill was second, and originality skill was last.

\section{The Second Question}

Is there a difference in the development of creative thinking skills among educational technology students due to the different pattern of infographics (image and text, image and sound) through the interactive smart board?

To answer this question, the mean and standard deviations were calculated for the scores obtained by students in the post-test of creative thinking as shown in Table (4):

Table 4

The mean score and standard deviation of the post score by creative thinking for method Descriptive Statistics

\begin{tabular}{lllll}
\hline & Group & Mean & Std. Deviation & $\mathrm{N}$ \\
\hline \multirow{3}{*}{ Post Fluency } & Sound \& Image & 77.0625 & 10.18148 & 16 \\
\cline { 2 - 5 } & Text \& Image & 62.1765 & 9.59971 & 17 \\
\cline { 2 - 5 } Post Flexibility & Total & 69.3939 & 12.31853 & 33 \\
\cline { 2 - 5 } & Sound \& Image & 15.1250 & 3.15964 & 16 \\
\cline { 2 - 5 } Text \& Image & 9.6471 & 3.01954 & 17 \\
\hline \multirow{2}{*}{ Post Originality } & Total & 12.3030 & 4.11920 & 33 \\
\hline \multirow{2}{*}{ Post total } & Sound \& Image & 13.7500 & 2.23607 & 16 \\
\cline { 2 - 5 } & Text \& Image & 8.0588 & 2.24918 & 17 \\
\hline & Total & 10.8182 & 3.63537 & 16 \\
\hline & Sound \& Image & 105.9375 & 12.00816 & 17 \\
\hline & Text \& Image & 79.8824 & 11.16290 & 17 \\
\hline
\end{tabular}


Table 4 showed a difference between the mean of post test scores of creative thinking skills for groups using the infographic pattern.

In order to reduce the statistical error, the pre- test scores were used as the covariate variable and a comparison was made between the groups (text and image \& sound and image) using the MANCOVA procedure (Table 6).

Table 5

MANCOVA of the post-test scores of students with different methods

\begin{tabular}{|c|c|c|c|c|c|c|}
\hline Source & $\begin{array}{l}\text { Dependent } \\
\text { Variable }\end{array}$ & $\begin{array}{l}\text { Type III Sum of } \\
\text { Squares }\end{array}$ & $\mathrm{df}$ & Mean Square & $\mathrm{F}$ & Sig. \\
\hline \multirow{4}{*}{ Group } & Post Fluency & 1875.385 & 1 & 1875.385 & 18.484 & .000 \\
\hline & Post Flexibility & 236.749 & 1 & 236.749 & 26.677 & .000 \\
\hline & Post Originality & 249.676 & 1 & 249.676 & 50.217 & .000 \\
\hline & Post total & 5549.283 & 1 & 5549.283 & 40.808 & .000 \\
\hline \multirow{4}{*}{ Error } & Post Fluency & 2840.908 & 28 & 101.461 & & \\
\hline & Post Flexibility & 248.494 & 28 & 8.875 & & \\
\hline & Post Originality & 139.216 & 28 & 4.972 & & \\
\hline & Post total & 3807.551 & 28 & 135.984 & & \\
\hline \multirow{4}{*}{ Total } & Post Fluency & 163768.000 & 33 & & & \\
\hline & Post Flexibility & 5538.000 & 33 & & & \\
\hline & Post Originality & 4285.000 & 33 & & & \\
\hline & Post total & 292201.000 & 33 & & & \\
\hline \multirow{4}{*}{ Corrected Total } & Post Fluency & 4855.879 & 32 & & & \\
\hline & Post Flexibility & 542.970 & 32 & & & \\
\hline & Post Originality & 422.909 & 32 & & & \\
\hline & Post total & 9752.242 & 32 & & & \\
\hline
\end{tabular}

Table 5 indicated that there were significant differences between (text and image $\&$ sound and image). Groups in the mean score of the post- test scores with F $(1.28)=$ 40.808, Mean Square $=5549.283$ and $\mathrm{p}=0.000$. of post test scores of creative thinking skills. $F(1.28)=18.484$, Mean Square $=1875.385$ and $p=0.000$. of post test scores of fluency skills. $\mathrm{F}(1.28)=26.677$, Mean Square $=236.749$ and $\mathrm{p}=0.000$. of post test scores of flexibility skills. And F (1.28) $=50.217$, Mean Square $=249.676$ and $\mathrm{p}=$ 0.000 . of post test scores of originalities, skills.

Results showed that the group students who exposed to sound and image outperformed their counterparts in the group who exposed to text and image.

\section{DISCUSSION}

The researcher explains the result as the interactive whiteboard is an interesting method to teach most of the educational materials through its features that help develop the capabilities of students, recall their previous experiences and information and use them in the current educational situations. The interactive whiteboard is a modern method and means to attract the attention of students during the educational process. This may be reflected in the modification of their tendencies and attitudes towards learning in general and the design of educational software in particular. That is the use of the interactive whiteboard and its characteristics through the display of infographics has a very 
significant impact in the development of spatial concepts in educational software, perhaps because the infographics displayed, which relied on the possibilities and characteristics of the interactive whiteboard. The designers took into account the individual differences among learners attracted their attention and raised their level of motivation and thinking through sensory stimuli that help the student imagine in depth the concepts contained in the lesson and put forward new ideas and acquire the speed of expression. Further, The the current result explains that the interactive whiteboard contains many shapes and drawings that stimulate the senses of sight and hearing through the infographics. This makes it more interactive and more comprehensive of the educational situation which in turn may reflect on the students' abilities to understand and analyze these audiovisual stimuli and try to distinguish and link them to previous information and experience. This is reflected in the development of students' creative thinking through the use of infographics that fit with the human sensory system by the use of visual and auditory multimedia and working to process them in WM. This is positively affecting their higher thinking skills, including creative thinking ones. The infographics presentation through the interactive whiteboard provided an atmosphere of interaction and cooperation among the students, which in turn allowed them to exchange experiences and knowledge and thus helped to develop their creative thinking skills (fluency, flexibility, authenticity) by generating ideas and using them to acquire new knowledge.

The use of infographics through the interactive whiteboard stimulate the senses of the learner through the ability to receive and process information better, which may lead to storage in the long-term memory, because infographics work to link the scientific material with graphics, colors, and sounds that form a familiar mental image to the student that may allow him to add details. This may reflect on the organization of ideas quickly and focus on priorities and classification of information and scientific concepts in the form of lists within the brain, which help to develop general thinking skills, skills of creative thinking in particular. Students learn and develop their creative thinking skills by organizing their ideas in a sequential hierarchy ranging from the most comprehensive to the least. They then link ideas to form new meaningful ones through deepening thinking to clarify the meanings in the infographics and thinking in several directions that are characteristics of creativity based on brainstorming skills to come up with new ideas by creating new relationships among things.

The theory of cognitive load can explain the probable cause of the noticeable positive impact of image and sound on creative thinking skills as the human information processing system consists of two channels: visual and audio. When the information is presented to students, the sensory memory receives it through the eye and ear (image, text, and sound). The information processing system processes the visual one in the visual channel and the audio information is processed in the audio one. Mayer (2001) noted that humans have a limited capacity for information that can be processed simultaneously in each channel. The audio and video channels process information in a balanced way. Neither channel is overloaded. 
Displaying infographics to students through the interactive whiteboard entered information through the visual channel only, limiting the student's cognitive abilities to process information in the visual one. The image and text compete for the limited knowledge resources in the visual channel because both enter through the eyes, making an excessive cognitive load on them while the auditory channel remains unused. Creative thinking cannot be achieved when the visual channel is overloaded. Further, students have a distraction between sources of information (Meyer, 2008), because the information is displayed simultaneously in text and image. This requires students to switch their attention back and forth between the printed text and the image, thus increasing the cognitive load on the visual channel due to the inability of the students to focus on the text and image at the same time. This, in turn, adversely affects the WM capacity as students who do not have sufficient memory capacity do not have the ability to achieve good results in learning and creative thinking.

The researcher believes that the design of infographics displayed through the interactive whiteboard should reduce the overload of the optical channel by replacing the printed text with spoken sound (verbal text) and image. The verbal text enters the cognitive system through the ears and process in the auditory channel. Mayer, Moreno, 2003, Mayer, 2001, and Sweller (1999) believe that using voice instead of text in multimedia presentation reduces overload on the visual channel and thus improves learning; this leads to improved learning, which may be reflected in the development of learners' creative thinking skills. In addition, this finding may be due to the fact that WM requires simultaneous temporary storage and processing of information necessary for cognitive tasks in the learning process. Hence, the use of sound and image is better handled in WM compared to the use of printed text and image where information processing is ineffective in WM. Better use and processing of audio and video and better reorganization of information help preserve and store information in the long-term memory. That is when students who use image and sound learn better than students who use text and the image at the level of creative thinking.

\section{RECOMMENDATIONS AND IMPLICATIONS FOR FUTURE RESEARCH}

The use of infographics through the interactive smart board has positive effects on the student's creative thinking skills: fluency, flexibility, and originality. The findings showed that the students using the infographics pattern (image \& sound) performed much better than students using the infographics pattern (image \& text) which was designed according to the cognitive load theory. The researcher recommends the need to integrate infographics through a display on an electronic interactive smart board designed according to the theory of cognitive load and information in the design and development of other fields. The pattern (image \& sound) of infographics through the interactive smart board has also shown an effective role in developing the creative thinking skills in students. Therefore, there should be more attention given to creative thinking skills in an academic environment in order to upgrade students' thinking skills in various specialties. The use of infographics through the interactive smart board should be applied to different samples and subjects and focus on the training of academic staff and students in this type of teaching method. As a review of using the 
cognitive load theory in infographics, its results help develop teaching strategies at universities. This study used creative thinking skills as dependent variables; future research suggests other variables, such as the cognitive style, learning patterns, visual thinking, student ability, and multiple intelligences; and the need to implement the integration strategy between the use of the infographics and the creative thinking skills when teaching students. The researcher recommends educators to pay more attention to developing infographics and creative thinking skills, holding workshops for teachers to train them in using these skills before they start work and in-service to enable them to use these skills in teaching. This training can provide a learning environment that can enable teachers to practice these skills. The researcher recommends educators to design imitation programs to develop the lacking skills in light of the students' needs, the requirements of the society, and the challenges of today. More research needs to be done into the effectiveness of using infographics in achieving better learning outcomes in various educational programs and courses.

\section{CONCLUSIONS}

This study shows that the arithmetic means and standard deviations of the degree of creative thinking skills of students who studied through infographics were moderate; fluency skill was ranked first; flexibility skill was second; and originality skill was last. Further, this study found that the use of infographic patterns (image \& sound) through the interactive smart board helped students perform much better creative thinking skills (fluency, flexibility, and originality) than students using infographic patterns (image \& text) through the interactive smart board. It gives support to the effect of the infographic pattern of creative thinking skills. In short, the study strongly indicated that the infographic pattern through an interactive smart board was effective in promoting better learning of the courses of designing educational software creative thinking skills; such as finding the main ideas, asking questions to collect more data, and being able to arrange patterns and find the relationships among objects in designing educational software subjects. It is suggested that blended learning should be integrated into all courseware on the learning of mathematics. Infographics should be considered in the instructional designer of preparing multimedia learning courseware for students. In general, all the students responded favorably to the development of the creative thinking skills using courseware-based infographic patterns which make it easier for students to discuss and communicate with lecturers. This helps them solve any problem they may meet.

\section{REFERENCES}

Abadi, N. (2014). The Cognitive Burden and Attached to The Ability of Self-Response University Students. Unpublished Master Thesis, Diyala University, College of Education.

Abdel Fattah, R. (2017). The Effect of Interactive Whiteboard in The Achievement of Knowledge of Educational Psychology And The Motivation Towards Learning. Karbala Scientific University, 15(2), 200 - 2017. 
Abo areban. (2017). The Effectivenees Of Using Infographictechnology (Illustrative Graphics - Animated Graphics) In Developing Genetic Problem-Solving Skills in Life Sciences Among Female Tenth Graders In Gaza. Unpublished Master Thesis, Islamic University.

Afify, M. (2018). The Effect of the Difference Between Infographic Designing Types (Static vs Animated) on Developing Visual Learning Designing Skills and Recognition of its Elements and Principles. International Journal of Emerging Technologies in Learning (iJET) 13(09), $204-223$.

Al azri, R. (2017). Using the Creative Thinking Skills by the Teachers of Grades 1-10 from the Educational Supervisors View in Al-Dhahira Governorate Schools. International Journal for Research in Education, 41(4), 83 - 114.

Al Eid, W. (2010). Analysis of Evaluation Activities for the 4th Grade in book of "Our beautiful language" according to creative thinking skills and how acquirement students to it. Unpublished Master Thesis, Islamic University.

Al hassan, I \& Al badwi, M. (2016). The Effect of Using the Smart Board in the Acquisition for the Pupils in the 8th. Class of the Basic Education Stage at Khartoum locality in the Lesson of Science in Our Life. Journal of the College of Basic Education for Educational and Human Sciences / University of Babylon, 26, 3 - 37.

Aldalalah, O. (2011). Effects of Multimedia-Based Instructional Design on the Learning and Attitude among Jadara University Students: A Cognitive Load Theory Outlook. Elixir Social Studies 40, 5314-5320.

Aldalalah, O. (2012). Modality Effects in Reducing Cognitive Loads in Multimedia Learning. International Journal of Learning and Development. 2(1), 603 - 612.

Aldalalah, O. Ababneh, Z. Bawaneh, A \& Alzubi, W. (2019). Effect of Augmented Reality and Simulation on the Achievement of Mathematics and Visual Thinking among students. International journal of emerging technologies in learnin, 18(14), 164-185.

Aldalalah, O., Shatat, F \& Ababneh, Z. (2019). The Impact of Blended Learning on the Development of the Cognitive and Metacognitive Thinking Skills in Mathematics of the (ECT) Students. JIRSEA Issue, 17(1), $16-42$.

Al-Otaibi, W. (2018). The Impact of using Instructional Infographic on Students' Achievement in English Language Grammar of First Intermediate Grade in Riyadh. Journal of Educational and Psychological Sciences, 8(2), 26 - 55.

Al-Qahtani, O \& Yousef, Y. (2015). The Effectiveness of a Proposed Procedural Program Based on Productive Habits of Mind in Developing Innovative Abilities Among Students of The University of Tabuk. Arab Journal for the Development of Excellence, 2 (11), $229-302$.

Alqrery, H. (2016). The Effectiveness of Teaching and Suggested Unit Using the Interactive Whiteboard in The Development of Mathematical Thinking Skill And 
Achievement Among Middle Schoolers In Jeddah. Journal of the Faculty of Education, Al-Azhar University, 168(3), 585 - 631.

Al-Shanti, R (1983). Implications of Validity and Stability of Torrance Tests Creative Thinking A Modified Image of The Jordanian Environment Verbal Testing A Formal Test, Unpublished Master Thesis, Jordanian University.

A'salmi, K \& Ambusaidi, A. (2016). The Effectiveness of Teaching Using the Interactive Whiteboard in Learning Science and the Development of the Cognitive Thinking Skills among Female Students of 10th grade in Basic Schools. An-Najah University Journal for Research (Humanities) 30(2), 335 - 380.

A'zuabi, S. (2011). Effective of A Program for Learning Using Interactive Whiteboard in Science Achievement Among Students of Grade Five in Kuwait. Educational Journal, 26(102), 393-399.

Bicen, H \& Beheshti, M. (2017). The Psychological Impact of Infographics in Education. BRAIN, 8(4), 99-108.

Çifçi, L. (2016). Effects of Infographics on Students Achievement and Attitude towards Geography Lessons. Journal of Education and Learning, 5(1), 154 - 166.

Davidovitch, N \& Yavich, R. (2017). The Effect of Smart Boards on the Cognition and Motivation of Students. Higher Education Studies, 7(1), 60 - 68.

Dunlap, C \& Lowenthal, R. (2016). Getting Graphic about Infographics: Design Lessons Learned from Popular Infographics. Journal of Visual Literacy, 3 (1), 42-59.

Ercan, O. (2014). The Effects of Multimedia Learning Material on Students' Academic Achievement and Attitudes Towards Science Courses. Journal of Baltic Science Education 13(5), $608-621$.

Ezzeldin, S. (2017). The Effectiveness of Using Graphic Organizer in Development of Achievement Reduction of Cognitive Lode Associated with Solving Algorithm Problems In Analytical Chemistry And Favored Learning Styles Among Female Secondary School Students In Saudi Arabia. International journal for research in education, 41(2), 77 - 124.

Islamoglu, H., Ay, O., Ilic, U., Mercimek, B., Donmez, P., Kuzu, A. \& Odabasi, F. (2015). Infographics: A new competency area for teacher candidates. Cypriot Journal of Educational Sciences, 10(1), 32-39.

Jbeili, I. (2014). The Effectiveness of Integrating Smart Board and Metacognitive Skills on Knowledge Achievement Related to Instructional Courseware Production Skills Among Instructional Technology Students. The Jordanian Journal of Educational Sciences, 10(1), 121-132.

Jeroui, A. (2014). The Effectiveness of a Proposed Training Program in The Development of Electronic Mind Mapping Skills Through Infographic and Visual 
Culture Skills of Pre-Service Teachers. Arab Studies in Education, Education and Psychology, 45 (4),

Khasawneh, F. (2015). Creative Thinking Process in Design. Derasat, Humanities and Social Sciences, 42(1), 1217 - 1227.

Mansour, I. (2015). The Effectiveness of Employs Interactive Whiteboard in The Scientific Concepts of Development, and The Skills of Visual Thinking Among ThirdGrade Students. Unpublished Master Thesis, Islamic University.

Matrix, S. \& Hodson, J. (2014). Teaching with Infographics: Practicing New Digital Competencies and Visual Literacies. Journal of Pedagogic Development, 3(2). 17-27.

Mayer, R. E., \& Moreno, R. (2003). Nine Ways to Reduce Cognitive Load In Multimedia Learning. Educational psychologist, 38(1), 43-52. doi:10.1207/S15326985EP38016.

Mayer, R. E. (2001). Multimedia Learning. New York, Cambridge university press.

Morsi, W. (2017). Effect of An Educational Program That Uses Smart Whiteboard in Developing Creative Thinking for Deaf Students. Journal of Studies in University Education, 35, 561 - 594.

Paas, F., Tuovinen, J. E., Tabbers, H. K. \& Van, P. (2003). Cognitive Load Measurement as A Means to Advance Cognitive Load Theory. Educational Psychologist, 38 (1), 63-71.

Sabab, A. (2016). Cognitive Load And Its Relationship of Mental Capacity According to The University Students Levels. Mustansiriya University - Journal of the College of Education, 6, 139 - 184.

Saifuddin, H. (2015). Manual Torrance Test for Formal creative Thinking (B). King Abdulaziz University - College of Arts and Humanities Department of Psychology.

Shaltout, M. (17 - 1 July 2019). Model for Educational infographics. The 7th International Scientific Conference of the Egyptian Computer Society, Port Said

Shaltout. M. (2016). Infographic from Planning to Production. Riyadh: Fahd National Library

Smiciklas, M. (2012). The Power of Infographics. Pearson education, inc, 800 East 96th Street, Indianapolis, Indiana 46240 USA.

Sousa, L., Richter, B \& Nel, C. (2017). The Effect of Multimedia Use on The Teaching and Learning of Social Sciences at Tertiary Level: A Case Study. Yesterday\&Today, 17, 1 - 22. http://dx.doi.org/10.17159/2223-0386/2017/n17a1.

Sweller, J. \& Chandler. (1994). Why Some Materials Are Difficult to Learn, Cognition and Instruction, 12(3), 185-233. 
Sweller, J. (2004). Instructional Design Consequences of An Analogy Between Evolution By Natural Selection And Human Cognitive Architecture. Instructional Science 32(1), 9-31.

Sweller, J. (2005). The Redundancy Principle in Multimedia Learning. In R. E. Mayer (Ed.), The Cambridge handbook of multimedia learning. Cambridge: Cambridge University Press.

Sweller, J. (2006). Discussion of Emerging Topics in Cognitive Load Research: Using Learner and Information Characteristics In The Design Of Powerful Learning Environments. Applied Cognitive Psychology, 20(2), 353-357.

Torrance, E., \& Goff, K. (1990). Fostering Academic Creativity in Gifted Students. ERIC Document Reproduction Service No: 321489

Yildırım (2016). Infographics for Educational Purposes: Their Structure, Properties and Reader Approaches. The Turkish Online Journal of Educational Technology, 15 (3), 98110 .

Yousef, R. (2019). The Effectiveness of a Program based on SCAMPER'S Model In developing Creative Thinking Skills among Students in the Tenth Grade. Jordan Journal of Educational Sciences, 2 - 29.

Zoubi, M. (2017). The Effect of Cognitive Load, Presentation, Organization and Presentation Time In Multimedia Environments On Remembering. International Journal of Educational and Psychological Sciences - Arab Foundation for Scientific Research and Human Development - Egypt, 5, 189 - 218. 